\title{
Communication \\ Liquid Crystal-Embedded Hollow Core Fiber Temperature Sensor in Fiber Ring Laser
}

\author{
Weihao Lin $\left.{ }^{1,2,+} \mathbb{(}\right)$, Shengjie Zhou ${ }^{1,+}$, Yibin Liu $^{1}\left(\mathbb{D}\right.$, Mang I. Vai ${ }^{2}$ and Liyang Shao ${ }^{1, *(\mathbb{C}}$ \\ 1 Department of Electrical and Electronic Engineering, Southern University of Science and Technology, \\ Shenzhen 518055, China; 11510630@mail.sustech.edu.cn (W.L.); 11812717@mail.sustech.edu.cn (S.Z.); \\ 11811808@mail.sustech.edu.cn (Y.L.) \\ 2 Department of Electrical and Computer Engineering, Faculty of Science and Technology, University of Macau, \\ Macau 999078, China; fstmiv@um.edu.mo \\ * Correspondence: shaoly@sustech.edu.cn; Tel.: +86-0755-8801-8136 \\ + The authors contributed equally to this paper.
}

check for updates

Citation: Lin, W.; Zhou, S.; Liu, Y.; Vai, M.I..; Shao, L. Liquid Crystal-Embedded Hollow Core Fiber Temperature Sensor in Fiber Ring Laser. Appl. Sci. 2021, 11, 7103. https://doi.org/10.3390/app11157103

Received: 1 July 2021

Accepted: 29 July 2021

Published: 31 July 2021

Publisher's Note: MDPI stays neutral with regard to jurisdictional claims in published maps and institutional affiliations.

Copyright: (c) 2021 by the authors. Licensee MDPI, Basel, Switzerland. This article is an open access article distributed under the terms and conditions of the Creative Commons Attribution (CC BY) license (https:// creativecommons.org/licenses/by/ $4.0 /)$.

\begin{abstract}
An optical fiber temperature sensor based on Mach-Zehnder interferometer and thermooptic effect of the liquid crystal (LC) in fiber ring laser (FRL) system is proposed and experimentally demonstrated. The LC is infiltrated into the core of hollow core fiber, and the resonant wavelength is more sensitive to temperature variation due to the interaction between the incident light and the cavity infiltrating liquid crystal with high thermal light coefficient. Meanwhile, the FRL system was further used to make the sensor have good performance in the case of high signal-to-noise ratio $(\sim 35 \mathrm{~dB})$, narrow half-height width $(\mathrm{FWHM}=0.15 \mathrm{~nm})$, and high sensitivity in the temperature range from $20{ }^{\circ} \mathrm{C}$ to $50{ }^{\circ} \mathrm{C}$, with the maximum sensitivity of $1.318 \mathrm{~nm} /{ }^{\circ} \mathrm{C}$. As far as we know, in the FRL system, the liquid crystal material has a better temperature sensing performance than the previous fiber. Nevertheless, the system has the advantages of good repeatability, low cost, simple production, small volume, high sensitivity. In marine microbial culture and detection, it is necessary to carry out high sensitivity measurement within a small temperature variation range. This reliable and excellent temperature performance has a potential application prospect.
\end{abstract}

Keywords: liquid crystal; fiber ring laser; fiber temperature sensor

\section{Introduction}

In recent years, optical fiber sensors have attracted much attention in aerospace engineering [1], manufacturing industries [2], and biological sensing regions [3]. Due to their specific merits of immunity to electromagnetic interference, miniaturization, high sensitivity, and flexibility [4]. Various kinds of sensors have been designed to measure temperature [5], electric field [6], biomolecule [7], curvature [8], etc. Among these optical fiber sensors, a variety of temperature measurement methods, such as Fabry-Perot interferometer [9], photonic crystal fiber (PCF) [10], tapered fiber [11], multimode interference (MMI) [12], and fiber Bragg grating (FBG) [13], have been extensively studied. Among them, hollow fiber has been widely concerned [14-18]. The thermal conductivity of the hollow cladding is different from that of the solid cladding, and it is easy to inject the thermosensitive liquid through the capillary effect, with low cost and high sensitivity. Wu et al. reported a compact MZI based on hollow fiber [19], which is used as a splitter and combiner to form a Mach-Zehnder interferometer for temperature detection. It achieves $30.92 \mathrm{pm} /{ }^{\circ} \mathrm{C}$. Zhang et al. reported a diaphragm free ultra-high temperature FPI sensor based on hollow fiber [20], which achieved a detection sensitivity of $15.2 \mathrm{pm} /{ }^{\circ} \mathrm{C}$ at $1000{ }^{\circ} \mathrm{C}$. Besides, Dong et al. proposed a temperature sensor with a sensitivity of $31.8 \mathrm{pm} /{ }^{\circ} \mathrm{C}$ based on hollow photonic band gap fiber with mode interference [21]. However, a common problem is that the sensor is limited by the large bandwidth of broadband light source and low signal-to-noise ratio. 
Recently, FRL system has been successfully developed as a temperature sensor. Compared with the traditional optical fiber temperature sensor using super continuous wideband light source, it has the advantages of narrow line width and high signal-to-noise ratio. Lin et al. proposed a fiber Mach-Zehnder interferometer sensor based on Er doped fiber peanut (EDFP) structure without using extra filter. The temperature sensitivity of the EDFP is $0.158 \mathrm{~nm} /{ }^{\circ} \mathrm{C}$ [22]. Besides, Yin et al. designed a temperature sensor based on single-mode-no-core-hollow-core-no-core-single-mode interferometer to measure the temperature variation. The temperature sensitivity up to $8.53 \mathrm{pm} /{ }^{\circ} \mathrm{C}$ [23]. A $2 \mu \mathrm{m}$ tapered seven-core fiber structure was used for temperature measurement in fiber ring laser [24]. The sensitivity is up to $-4 \mathrm{pm} /{ }^{\circ} \mathrm{C}$ and the range is $35^{\circ} \mathrm{C}$ to $70^{\circ} \mathrm{C}$. However, due to the limitation of the thermal expansion coefficient of the fiber, the detection sensitivity of these structures has not reached $\sim \mathrm{nm} /{ }^{\circ} \mathrm{C}$ magnitude.

In this paper, we propose and experimentally demonstrate a highly sensitivity temperature sensor based on liquid crystal filled HCF in FRL system. The device consists of a hollow core fiber (HCF) filled with LC-E7 welded between two core-less fibers. The pores at the welding site collapse to form MZI. When the external temperature changes, the refractive index (RI) of the liquid crystal changes due to the thermo-optic effect, and the corresponding resonant wavelength also changes accordingly. In the FRL system, the output resonance spectrum of the device is demodulated by MZI, and the temperature tuning ability of the device is verified. The resonance wavelength is offset with temperature, and the maximum sensitivity is $1.318 \mathrm{~nm} /{ }^{\circ} \mathrm{C}$. By changing the HCF size more modes can be excited and higher sensitivity can be obtained. The device is easy to manufacture because only simple filling methods and processes are used. In addition, the liquid crystal and optical fiber used in the device are both economical and efficient. These advantages make the device competitive in practical applications such as high sensitivity temperature sensors, high efficiency biomolecule culture, and environmental temperature monitoring.

\section{Working Principle and Experimental Setup}

The schematic diagram of the optical fiber sensor is shown in Figure 1. The structure consists of a hollow optical fiber (HCF) containing a liquid crystal (E7, King Optronics Co., Ltd., Suzhou, China). Both ends are coreless fiber with an equal length of $1.5 \mathrm{~mm}$. Single mode fiber (SMF), no core fiber (NCF), and HCF are coaxially connected by commercial fusers (FSM-60S, Fujikura, Tokyo, Japan). The HCF has an outside diameter of $125 \mu \mathrm{m}$ and an inside diameter of $80 \mu \mathrm{m}$ with a pure silicon capillary length of $10 \mathrm{~mm}$. Then, through the set process and parameters, the splicing parameter conditions are modified to avoid the excessive collapse of pores and ensure the appropriate strength. Accurate length cutting of NCF and HCF with vernier calipers and fiber cutters. As shown in Figure 1 , the first segment of the NCF, which acts as a beam splitter, outputs part of the light channeled in the SMF to the higher-order mode, since the lead-in of SMF, NCF, and HCF has a circular cross and the fusion splice between them is aligned accurately. When light is emitted into HCF, due to the mode field mismatch, a portion of the fundamental mode (LP01) beam is coupled to the higher order mode, and then the beam is further emitted into HCF. As the refractive index of the core mode and the cladding mode are different, the interference occurs when the two beams recombine. The proposed interferometer involves the interference of the fundamental mode and the higher mode. The two-mode interference model is used to simplify the analysis of the transmitted light intensity:

$$
I=I_{1}+I_{2}+2 \sqrt{I_{1} I_{2}} \cos \Delta \varphi
$$

where $I$ is the transmitted light intensity of NHN structure, and $I_{1}$ and $I_{2}$ are the intensity of core mode and cladding mode, respectively. $\Delta \varphi$ is the phase difference between two beams and can be represented as:

$$
\Delta \varphi=\frac{2 \pi l}{\lambda}\left(n_{2}-n_{1}\right)=\frac{2 \pi l}{\lambda} \Delta n
$$


where $\lambda$ is the wavelength of free space light, $\mathrm{L}$ is the length of HCF, $n_{1}$ and $n_{2}$ are the RI of the air cavity mode and the silicon mode, respectively, and $\Delta n$ is the RI difference of the two interference beams. Liquid crystal molecules are generally rigid rod-like molecules. Due to the different molecular groups connected to the head, tail, and side of the molecule, the liquid crystal molecules have different properties in the two directions of the long axis and the short axis, and become polar molecules. Ordered by intermolecular forces, the long axis of liquid crystal molecules is always parallel to each other, or has a preferred direction, and the center of mass is free. When the light propagates in the liquid crystal, the optical refractive index anisotropy, namely birefringence, occurs, and the refractive index $(n)$ is affected by the molecular structure of the liquid crystal. When light passes through a uniaxial crystal, the refractive index of unusual light $\left(n_{\mathrm{e}}\right)$ is greater than that of ordinary light $\left(n_{0}\right)$. The results show that the propagation velocity of light in liquid crystal is ve $<\mathrm{v} 0$; the change of temperature field leads to the change of $\Delta n$ value, resulting in the deviation of interference peak. It shows that there are different propagation velocities for light vibration in different directions.

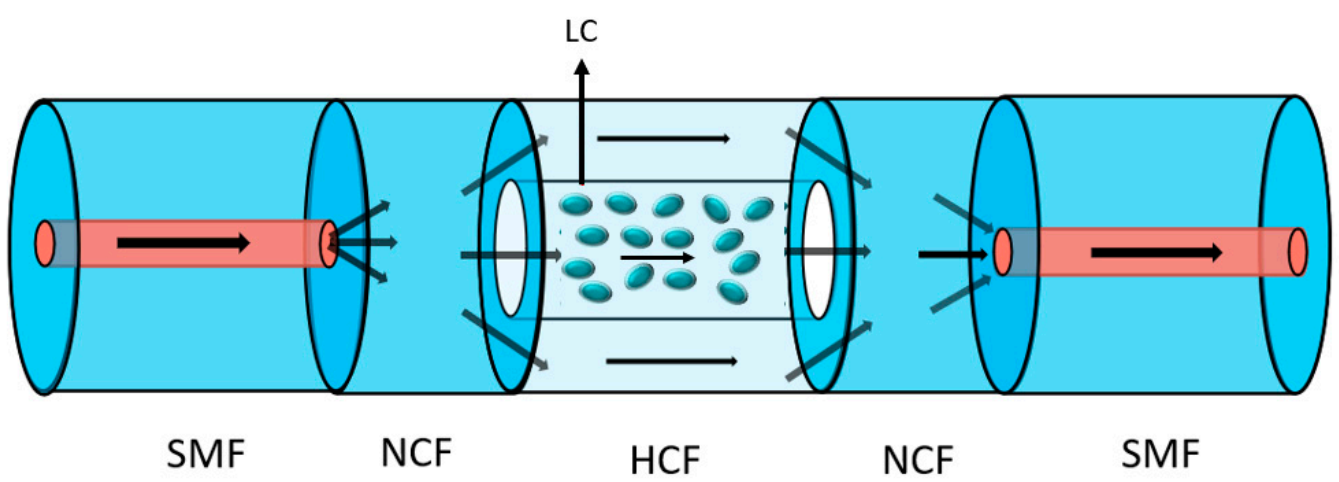

Figure 1. Configuration of LC filled NC-HC-NC structure based modal interferometer.

NHN structure is sensitive to temperature, and thermophonic effect reflects the change of RI of liquid crystal. It is worth noting that the liquid crystals are almost completely thermally induced. The transition between different liquid crystal states within a certain concentration range is called an intermediate phase. In this regard, LC is an ideal choice for implementing a tunable hollow fiber (LC-HCF) temperature sensor. As shown in Figure 2, the anisotropic optical properties of E7 can be described by the special and ordinary refractive indices of $n_{e}$ and $n_{o}$. In nematic phase, $n_{o}$ increases and $n_{e}$ decreases with the increase of temperature. The thermo-optical coefficients of these two indexes are in the range of $10^{4}-10^{3} \mathrm{RIU} /{ }^{\circ} \mathrm{C}$, which is similar to that of isotropic optical liquids. In this case, the thermo-optic tuning of the liquid crystal compound acts more as an additional degree of freedom to tune the response of the photonic crystal fiber filled with the liquid crystal. In addition, the flow process of E7 induces the orientation of major molecules along the fiber axis. With the increase of temperature, the RI value of LC decreases, while the RI value of cavity mold is basically unchanged. According to Equation (2), as the temperature increases, the interference pattern will shift to the short-wave direction. With the increase of temperature, the fundamental mode distribution corresponding to the mode field penetrating the cladding decreases obviously, which indicates that the filled liquid crystal fiber is very sensitive to the change of ambient temperature. 


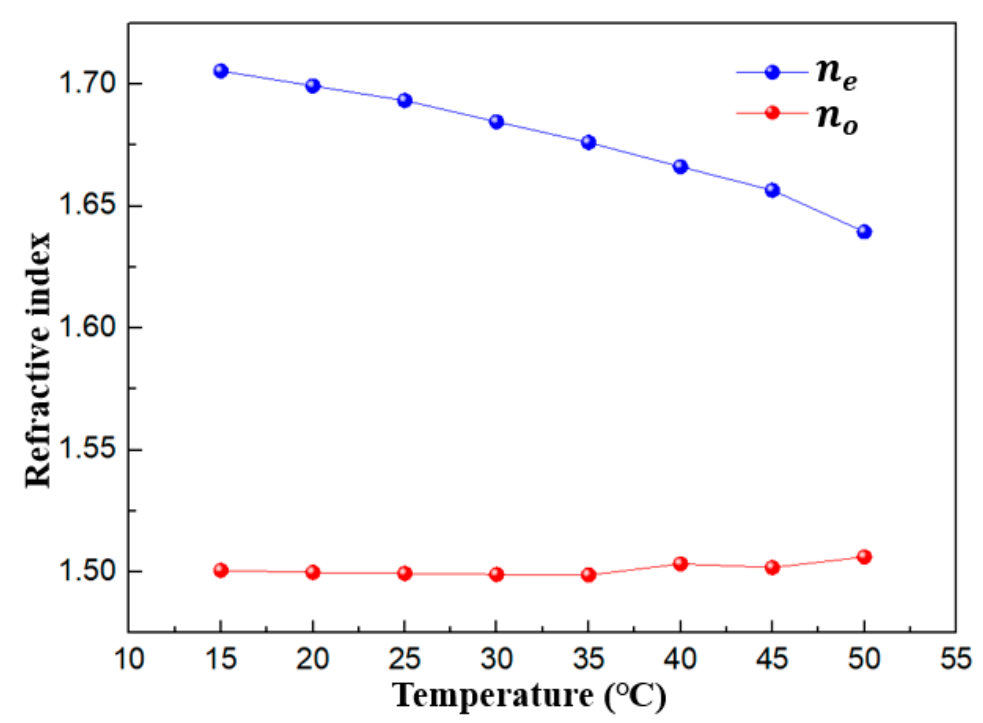

Figure 2. Temperature dependence of the refractive index of the nematic E7 liquid crystal.

The distributions of the fundamental mode and the effective mode area $A_{e f f}$ can be calculated by [25]:

$$
A_{e f f}=\frac{\left(\iint|E(x, y)|^{2} d x d y\right)^{2}}{\iint|E(x, y)|^{4} d x d y}
$$

where $E(x, y)$ represents the two-dimensional electric field distribution of the fundamental mode.

Although the liquid crystal sequence is not completely parallel to the fiber axis, as shown in Figure 2, the refractive index changes linearly on the whole. When the liquid crystal reaches near the clear point $\left(56^{\circ} \mathrm{C}\right)$, the refractive index changes greatly, and the effective refractive index does not change linearly. This will lead to the mutation of the interference peak, which is manifested in the FRL system, leading to laser mode hopping. Therefore, the temperature change between $20^{\circ} \mathrm{C}$ and $50{ }^{\circ} \mathrm{C}$ is selected in the experiment. Due to the linear change of refractive index, the directional translation of the output spectrum is caused. Therefore, although the orientation of the liquid crystal is not completely fixed, the refractive index of the liquid crystal at every temperature is a fixed value, ensuring the stability of the system.

The temperature response of fiber filled with liquid crystal was studied by using a length of $10 \mathrm{~mm} \mathrm{HCF}$ and two segments with a length of $1.5 \mathrm{~mm}$ NCF. In our experiment, one end of the $20 \mathrm{~mm}$ length HCF was sealed in a pressure tube connected to the syringe, and the other end was immersed in a bottle containing E7, as shown in Figure 3. The syringe is fixed on an electrically controlled moving table to produce a uniform differential pressure. When the plunger of the syringe is pulled, it creates a vacuum pressure in the tube. The liquid crystal filler is sucked into HCF with an injector and the HCF is cut with a cutter. It should be noted that the filling rate also depends on the material properties of the fluid, such as density and viscosity. Large diameter pores are distributed along the fiber core, and the high refractive index difference between the liquid crystal and the glass makes the liquid crystal become a multimode waveguide. When the phase matching condition is satisfied, the fundamental mode in the fiber core is coupled with the guide mode in the liquid waveguide, resulting in the coupling of light to the liquid waveguide at the phase matching wavelength. 


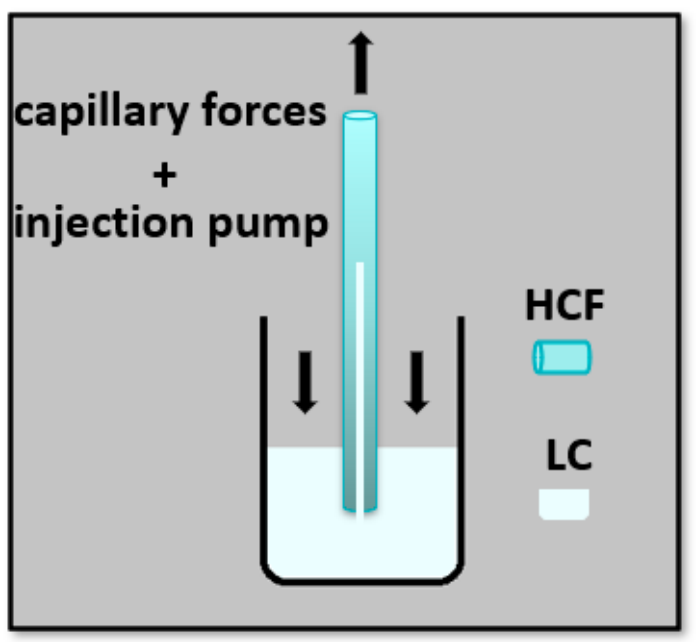

Figure 3. Schematic diagram for filling a liquid crystal into an HCF.

The pre-experiment device is shown in Figure 4. We splice an NCF at each end of the HCF filled with the liquid crystal. In order to reduce splicing loss, a negative pressure is applied to the other end of HCF before splicing, and the liquid crystal rod is moved a few millimeters to the inside of the fiber, so that the liquid crystal in the fiber will not be carbonized during discharge welding. The excess HCF is then cut off with a cutter and splice with NCF. The transmission spectra of the samples were measured with amplified spontaneous emission and a spectrum analyzer (OSA, AQ7360B, Yokogawa, Tokyo, Japan).

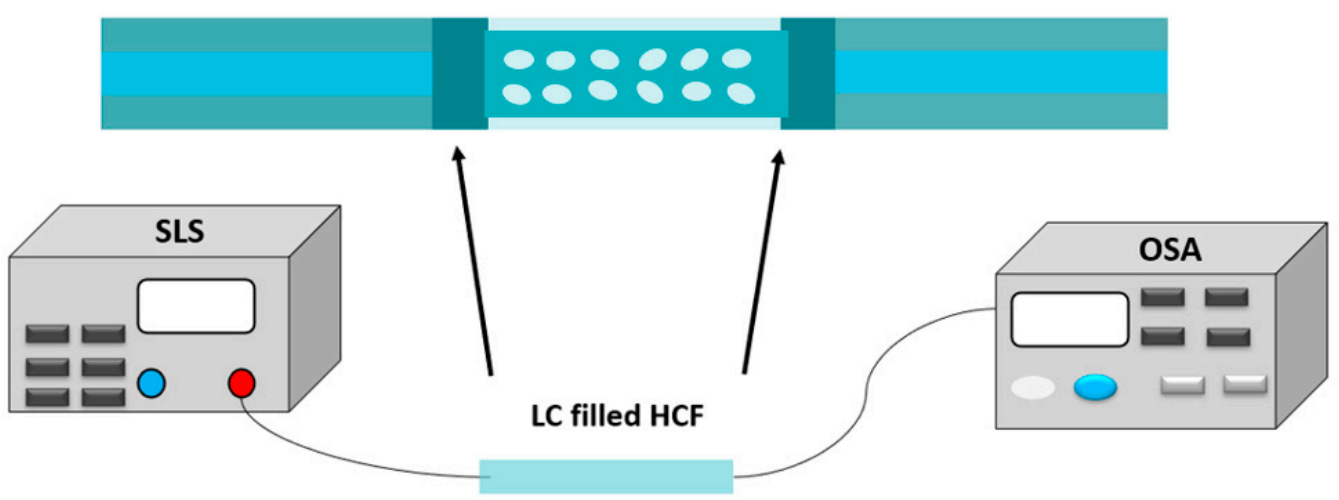

Figure 4. Schematic diagram of the pre-experimental setup. SLS: supercontinuum light source.

The structure diagram of fiber optic ring temperature sensor is shown in Figure 5. The $980 \mathrm{~nm}$ laser diode is used as the pump source and is connected to the $1.6 \mathrm{~m}$ erbium-doped fiber (EDF) via a $980 / 1550 \mathrm{~nm}$ wavelength division multiplexer (WDM). The function of the isolator is to suppress un-reflected light and prevent space hole burning. The light is then transmitted to an $10 \mathrm{~mm}$ long HCF filled with an E7 liquid crystal, which serves as both a wavelength selection filter and a temperature sensing head. After that, the output spectrum is connected to a 10:90 coupler, in which $10 \%$ of the light is extracted to the spectrometer (OSA) and the other portion is fed back to the laser cavity. 


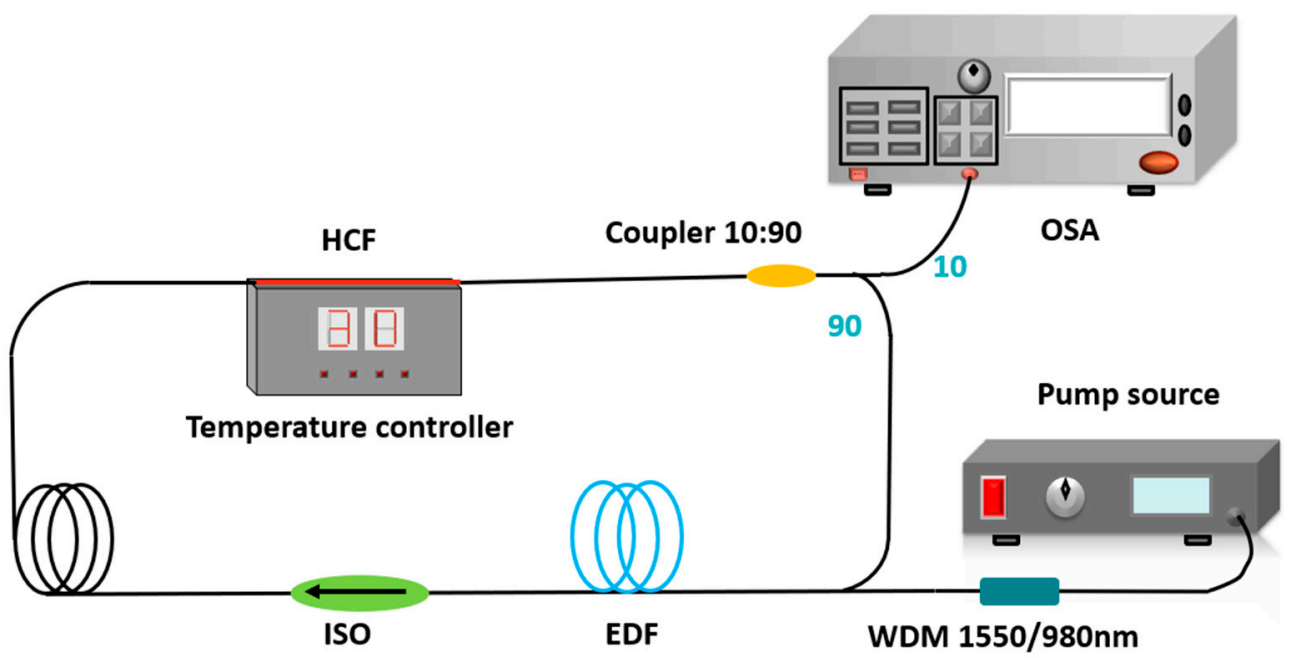

Figure 5. The schematic configuration of the proposed FRL temperature sensor system.

\section{Results}

Firstly, the temperature response of the structure in the supercontinuum light source is studied. Temperatures range from $20^{\circ} \mathrm{C}$ to $30^{\circ} \mathrm{C}$. Figure 6 a shows the resonant wavelength excursions corresponding to different temperatures. As shown in Figure 6a, with the increase of temperature, the transmission spectrum moves to the short-wave direction. There is a good linear relationship between temperature and wavelength, as shown in Figure $6 \mathrm{~b}$. The temperature sensitivity of the structure from $20^{\circ} \mathrm{C}$ to $30{ }^{\circ} \mathrm{C} . \mathrm{HCF}$ is $-1.041 \mathrm{~nm} /{ }^{\circ} \mathrm{C}$, which shows that the blue shift of the spectrum occurs with the increase of temperature, which is consistent with Equation (2). In addition, it should be noted that in the experimental results, each data point is the mean of at least five independent measurements, and the error bar represents the standard deviation of the mean. The error line is small and the experiment repeatability is good.

(a)

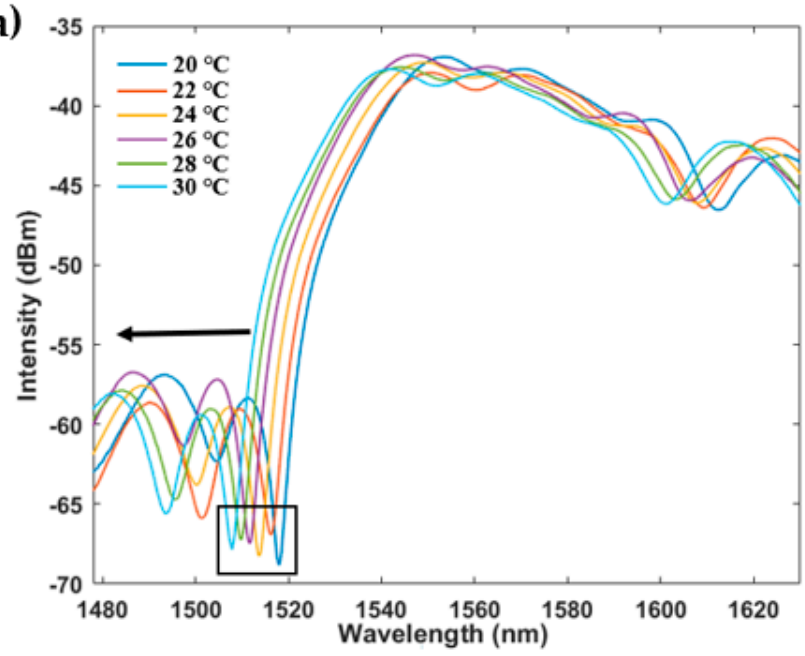

(b)

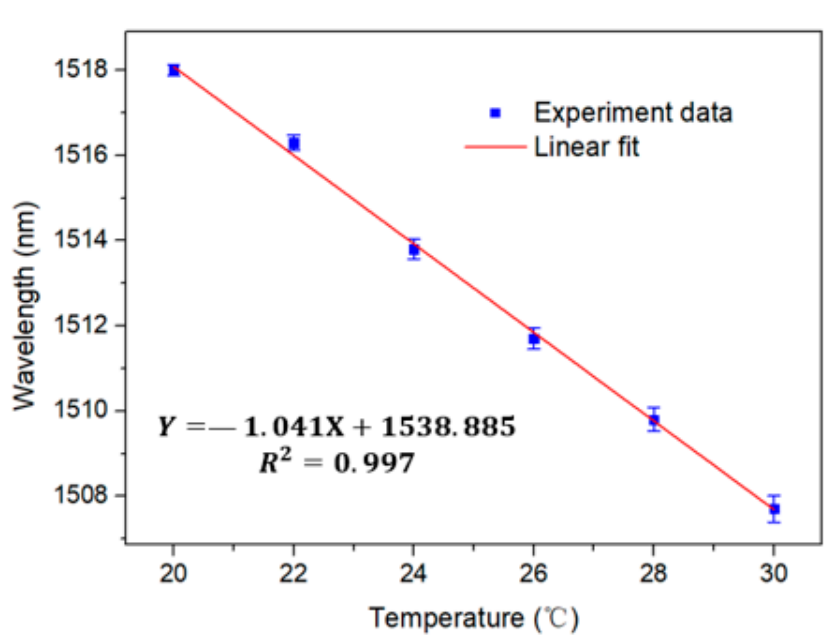

Figure 6. Temperature response of the LC filled HCF structure in ASE source. (a) Transmission spectra of temperature from $20^{\circ} \mathrm{C}$ to $30^{\circ} \mathrm{C} ;(\mathbf{b})$ relationship between the resonant wavelength response and the temperature.

The measurement range is from $20^{\circ} \mathrm{C}$ to $30^{\circ} \mathrm{C}$ according to Step $2{ }^{\circ} \mathrm{C}$. The emission spectra of the fiber ring cavity at different temperatures are shown in Figure 7a,b. With the increase of temperature, the blue shift of the spectrum occurs, which is consistent with the Equation (2). Its sensitivity is shown in Figure $7 \mathrm{~b}$. The calculated laser spectral sensitivity is $1.181 \mathrm{~nm} /{ }^{\circ} \mathrm{C}$. In addition, the correlation coefficient in Figure $7 \mathrm{~b}$ is 0.996 , indicating a 
good linear relationship with the external temperature. It can be observed that there is an error of about $0.14 \mathrm{~nm} /{ }^{\circ} \mathrm{C}$ from the ASE measurement, as shown in Figure 6. This may be caused by the deviation of the selected peak value due to the wide interference spectrum FWHM. Besides, as can be seen from Figure 7a, the SNR of FRL system is greater than $35 \mathrm{~dB}$, and the $3 \mathrm{~dB}$ bandwidth is less than $0.15 \mathrm{~nm}$. Furthermore, the response of temperature in a wide range is also discussed. Figure $8 \mathrm{a}$ shows the variation of emission wavelength with temperature (from $20^{\circ} \mathrm{C}$ to $50^{\circ} \mathrm{C}$ ). The fitting curve is shown in Figure $8 \mathrm{~b}$. Temperature sensitivity of $1.318 \mathrm{~nm} /{ }^{\circ} \mathrm{C}$ can be obtained by wavelength modulation. The results are slightly higher than those shown in Figure 7. This may be because the more the liquid crystal refractive index changes, as the temperature increases. However, in Figures $7 \mathrm{a}$ and $8 \mathrm{a}$, good consistency is maintained when the temperature range varies between $20^{\circ} \mathrm{C}$ and $30^{\circ} \mathrm{C}$. At $30^{\circ} \mathrm{C}$, the wavelength corresponding to $1538.023 \mathrm{~nm}$ and $1538.011 \mathrm{~nm}$, respectively.
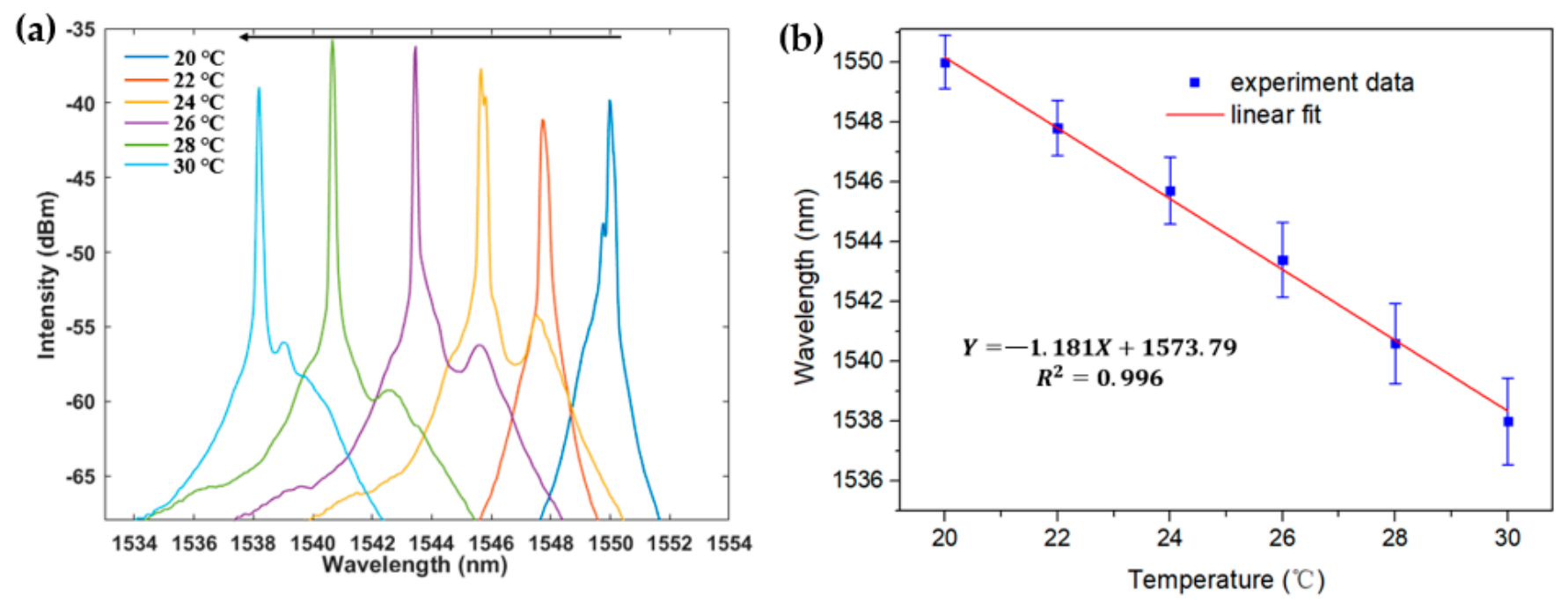

Figure 7. Temperature response of the LC filled HCF structure in FRL. (a)Transmission spectra of the fiber laser temperature sensor system when $\mathrm{T}$ changes from $20^{\circ} \mathrm{C}$ to $30^{\circ} \mathrm{C}$ with the steps of $2{ }^{\circ} \mathrm{C}$. (b) Variations of the emission wavelength.
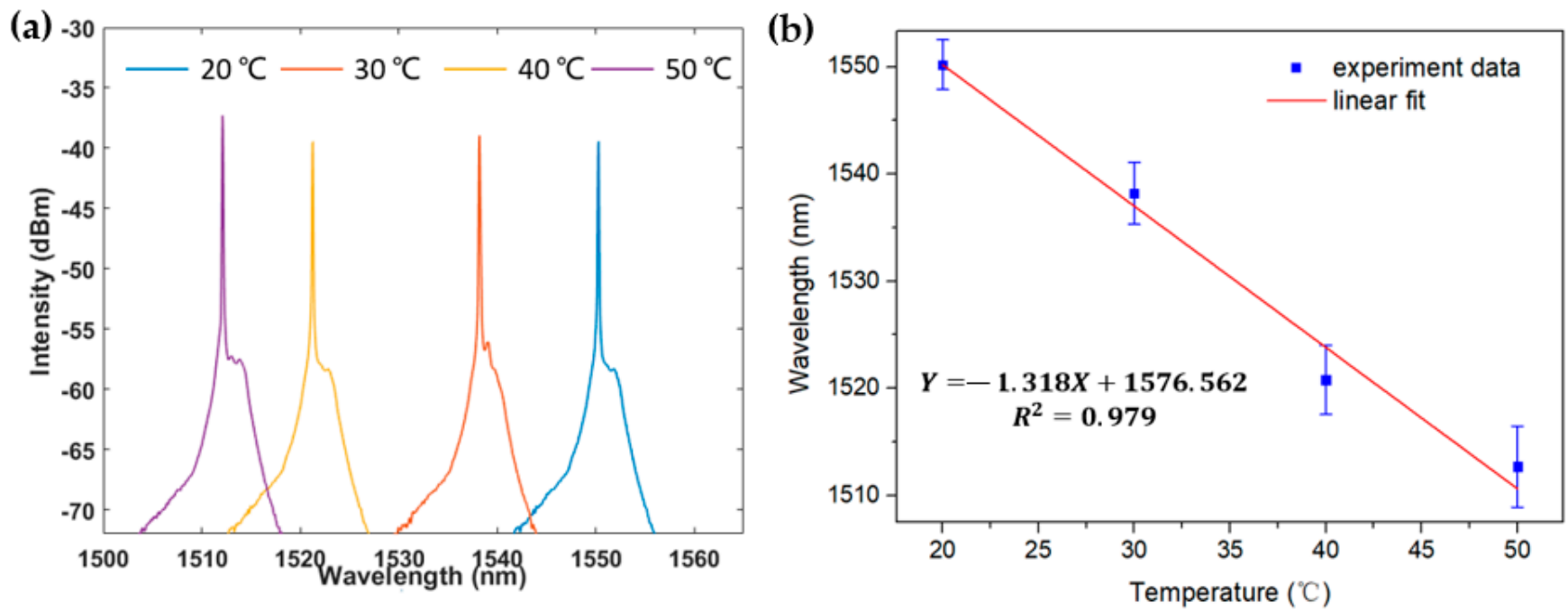

Figure 8. Temperature response of the LC filled HCF structure in FRL. (a) Transmission spectra of the fiber laser temperature sensor system when $\mathrm{T}$ changes from $20^{\circ} \mathrm{C}$ to $50^{\circ} \mathrm{C}$ with the steps of $10^{\circ} \mathrm{C}$. (b) Variations of the emission wavelength.

To quantitatively analyze the temporal stability of the sensor, wavelength drift and power fluctuation are plotted in Figure 9. The test was carried out at $20^{\circ} \mathrm{C}$. As can be 
seen from Figure 9, the maximum wavelength shift and power fluctuation of the laser line were $0.132 \mathrm{~nm}$ and $0.32 \mathrm{~dB}$, respectively. Without affecting the measurement results, the vibration of SNHNS structure in the FRL system can introduce the power change, and the power change can be mitigated by good encapsulation. This is another problem worth exploring. This problem can be solved with a compact and robust package to protect fragile uncoated fiber optic sensors, such as external hollow capillaries or embedded grooves.

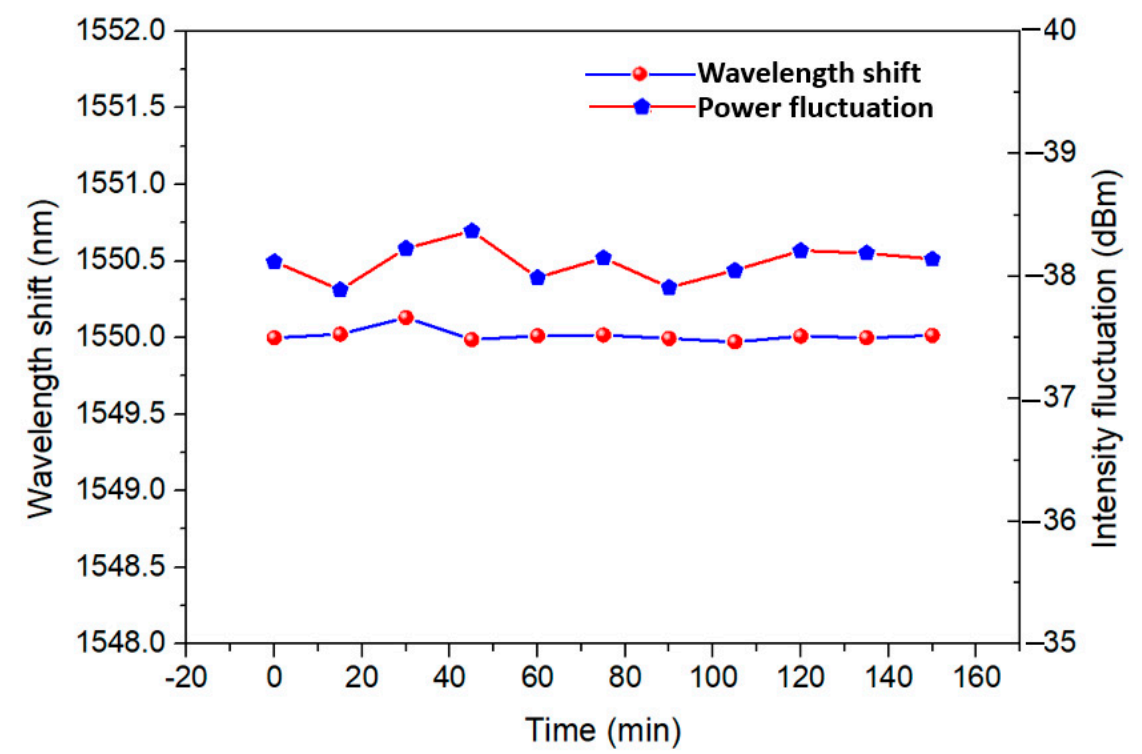

Figure 9. Test for time stability of wavelength shift and power fluctuation.

Since other liquid such as silicon oil has a similar isotropic refractive index variation with temperature. Replacing liquid crystal with silicone oil is an effective method for temperature measurement [26-29]. However, limited by the material properties of silicone oil itself, it has the following inevitable disadvantages: poor lubricity; the high solubility of gas is difficult to achieve gas sealing device; certain hygroscopicity; and after adding water, performance decline. Besides, the surface tension is small and easy to leak. Liquid crystals are still one of the best choices for temperature measurement.

Besides, surface treatments of the inner solid surface to induce planar alignment is an effective way to fixed liquid crystal orientation [30]. However, surface treatment inside optical fibers often require polishing or drilling. This greatly reduces the stability of the system. In addition, the exposed fiber is easily affected by dust in the air, which reduces the consistency of orientation. At the same time, due to the complex surface treatment process, the cost is high. Therefore, we do not choose to preprocess the fiber surface in this work.

\section{Conclusions}

A fiber ring laser temperature sensor is presented experimentally. The liquid crystal filled MZ interferometer of single-mode-no-core-hollow-core-no-core-single-mode structure is embedded into the fiber ring laser as sensing element and filter. Consequently, the laser possesses the ability of temperature detection. The characteristics of temperature is tested and the sensitivities is $-1.181 \mathrm{~nm} /{ }^{\circ} \mathrm{C}$ and $-1.318 \mathrm{~nm} /{ }^{\circ} \mathrm{C}$, respectively. Additionally, the good signal-to-noise ratio of $35 \mathrm{~dB}$, narrow $3 \mathrm{~dB}$ bandwidth of $0.15 \mathrm{~nm}$ are achieved for temperature measurement. In addition, the fiber ring laser sensor has the characteristics of small size, low cost, and convenient manufacture, which makes it a good choice in the practical application of fiber sensor.

Author Contributions: Conceptualization, W.L. and S.Z.; methodology, W.L.; validation, Y.L.; formal analysis, L.S.; investigation, M.I.V.; resources, S.Z.; data curation, W.L.; writing-original draft 
preparation, S.Z.; writing-review and editing, W.L.; supervision, L.S.; project administration, L.S.; funding acquisition, L.S. All authors have read and agreed to the published version of the manuscript.

Funding: This work was supported by the startup fund from Southern University of Science and Technology and Shenzhen government.

Institutional Review Board Statement: Not applicable.

Informed Consent Statement: Not applicable.

Data Availability Statement: Not applicable.

Conflicts of Interest: The authors declare no conflict of interest.

\section{References}

1. Beranek, M.W.; Chan, E.Y.; Chiu-Chao, C.; Davido, K.W.; Hager, H.E.; Chi-Shain, H.; Koshinz, D.G.; Rassaian, M.; Soares, H.P.; St Pierre, R.L.; et al. Passive alignment optical subassemblies for military/aerospace fiber-optic transmitter/receiver modules. IEEE Trans. Adv. Packag. 2000, 23, 461-469. [CrossRef]

2. Culshaw, B. Optical Fiber Sensor Technologies: Opportunities and-Perhaps-Pitfalls. J. Lightwave Technol. 2004, 22 , 39-50. [CrossRef]

3. Perezcampos Mayoral, C.; Gutierrez Gutierrez, J.; Cano Perez, J.L.; Vargas Trevino, M.; Gallegos Velasco, I.B.; Hernandez Cruz, P.A.; Torres Rosas, R.; Tepech Carrillo, L.; Arnaud Rios, J.; Apreza, E.L.; et al. Fiber Optic Sensors for Vital Signs Monitoring. A Review of Its Practicality in the Health Field. Biosensors 2021, 11, 58. [CrossRef] [PubMed]

4. Huang, X.F.; Chen, Z.M.; Shao, L.Y.; Cen, K.F.; Sheng, D.R.; Chen, J.; Zhou, H. Design and characteristics of refractive index sensor based on thinned and microstructure fiber Bragg grating. Appl. Opt. 2008, 47, 504-511. [CrossRef] [PubMed]

5. Shao, L.-Y.; Luo, Y.; Zhang, Z.; Zou, X.; Luo, B.; Pan, W.; Yan, L. Sensitivity-enhanced temperature sensor with cascaded fiber optic Sagnac interferometers based on Vernier-effect. Opt. Commun. 2015, 336, 73-76. [CrossRef]

6. Sharma, I.; Roy Chaudhuri, P. A new approach to sensing low electric field using optical fibers' beam-deflection configuration with BiFe0.9Co0.1O3 nanoparticles as probe and determination of polarisation. Opt. Fiber Technol. 2021, 62, 102472. [CrossRef]

7. Yang, W.; Yu, J.; Xi, X.; Sun, Y.; Shen, Y.; Yue, W.; Zhang, C.; Jiang, S. Preparation of Graphene/ITO Nanorod Metamaterial/UBent-Annealing Fiber Sensor and DNA Biomolecule Detection. Nanomaterials 2019, 9, 1154. [CrossRef]

8. Gong, Y.; Zhao, T.; Rao, Y.-J.; Wu, Y. All-Fiber Curvature Sensor Based on Multimode Interference. IEEE Photonics Technol. Lett. 2011, 23, 679-681. [CrossRef]

9. Liu, Y.; Wang, Y.; Yang, D.; Wu, J.; Zhang, T.; Yu, D.; Zhenan, J.; Fu, H. Hollow-Core Fiber-Based All-Fiber FPI Sensor for Simultaneous Measurement of Air Pressure and Temperature. IEEE Sens. J. 2019, 19, 11236-11241. [CrossRef]

10. Guo, J.; Yang, Q.; Cui, W.; Zou, X.; Yue, Y.; Wang, C.; Li, R.; Liu, Y. Research on a New Type of Biological Solution Fiber Sensor Based on Hybrid-PCF. IEEE Sens. J. 2021, 21, 16006-16014.

11. Yang, X.; Bandyopadhyay, S.; Shao, L.-Y.; Xiao, D.; Gu, G.; Song, Z. Side-Polished DBR Fiber Laser with Enhanced Sensitivity for Axial Force and Refractive Index Measurement. IEEE Photonics J. 2019, 11, 1-10. [CrossRef]

12. Mohd Noor, M.Y.; Azmi, A.I.; Abdullah, A.S.; Mohd Supa'at, A.S.; Mohd Kassim, N.; Ibrahim, M.H.; Ngajikin, N.H. High Sensitivity of Balloon-Like Bent MMI Fiber Low-Temperature Sensor. IEEE Photonics Technol. Lett. 2015, 27, 1989-1992. [CrossRef]

13. Gu, B.; Yin, M.; Zhang, A.P.; Qian, J.; He, S. Optical fiber relative humidity sensor based on FBG incorporated thin-core fiber modal interferometer. Opt Express 2011, 19, 4140-4146. [CrossRef] [PubMed]

14. Shi, Q.; Wang, Z.; Jin, L.; Li, Y.; Zhang, H.; Lu, F.; Kai, G.; Dong, X. A Hollow-Core Photonic Crystal Fiber Cavity Based Multiplexed Fabry-PÉrot Interferometric Strain Sensor System. IEEE Photonics Technol. Lett. 2008, 20, 1329-1331. [CrossRef]

15. Aref, S.H.; Amezcua-Correa, R.; Carvalho, J.P.; Frazao, O.; Caldas, P.; Santos, J.L.; Araujo, F.M.; Latifi, H.; Farahi, F.; Ferreira, L.A.; et al. Modal interferometer based on hollow-core photonic crystal fiber for strain and temperature measurement. Opt. Express 2009, 17, 18669-18675. [CrossRef]

16. Rao, Y.J.; Zhu, T.; Yang, X.C.; Duan, D.W. In-line fiber-optic etalon formed by hollow-core photonic crystal fiber. Opt. Lett. 2007, 32, 2662-2664. [CrossRef] [PubMed]

17. Kim, B.H.; Lee, S.H.; Lin, A.; Lee, C.L.; Lee, J.; Han, W.T. Large temperature sensitivity of Sagnac loop interferometer based on the birefringent holey fiber filled with metal indium. Opt. Express 2009, 17, 1789-1794. [CrossRef] [PubMed]

18. Chesini, G.; Osorio, J.H.; Serrao, V.A.; Franco, M.A.R.; Cordeiro, C.M.B. Metal-Filled Embedded-Core Capillary Fibers as Highly Sensitive Temperature Sensors. IEEE Sens. Lett. 2018, 2, 1-4. [CrossRef]

19. Wu, Y.; Yang, Y.; Jin, W.; Shen, Y.; Jian, S. Compact Mach-Zehnder interferometer-based no-core fiber hollow-core fiber no-core fiber structure. Opt. Eng. 2017, 56, 030501. [CrossRef]

20. Zhang, Z.; Xu, B.; Zhou, M.; Bao, W.; Xu, X.; Wang, Y.; He, J.; Wang, Y. Hollow-Core Fiber-Tip Interferometric High-Temperature Sensor Operating at 1100 degrees $C$ with High Linearity. Micromachines 2021, 12, 234. [CrossRef]

21. Gong, H.; Chan, C.C.; Zhang, Y.; Wong, W.; Dong, X. Temperature Sensor Based on Modal Interference in Hollow-Core Photonic Bandgap Fiber With Collapse Splicing. IEEE Sens. J. 2012, 12, 1421-1424. [CrossRef] 
22. Lin, W.; Shao, L.-Y.; Vai, M.I.; Shum, P.P.; Liu, S.; Liu, Y.; Zhao, F.; Xiao, D.; Liu, Y.; Tan, Y.; et al. In-Fiber Mach-Zehnder Interferometer Sensor Based on Er Doped Fiber Peanut Structure in Fiber Ring Laser. J. Lightwave Technol. 2021, 39, 3350-3357. [CrossRef]

23. Yin, B.; Wu, S.; Wang, M.; Liu, W.; Li, H.; Wu, B.; Wang, Q. High-sensitivity refractive index and temperature sensor based on cascaded dual-wavelength fiber laser and SNHNS interferometer. Opt. Express 2019, 27, 252-264. [CrossRef] [PubMed]

24. Wang, Y.; Chen, Z.; Chen, W.; Zhang, X. Refractive index and temperature sensor based on fiber ring laser with tapered seven core fiber structure in $2 \mu \mathrm{m}$ band. Opt. Fiber Technol. 2021, 61, 102388. [CrossRef]

25. Sun, B.; Zhao, J.; Wang, Y.; Huang, Y.; Luo, D.; Wang, C.; He, J.; Liao, C.; Yin, G.; Zhou, J.; et al. Broadband Thermo-Optic Switching Effect Based on Liquid Crystal Infiltrated Photonic Crystal Fibers. IEEE Photonics J. 2015, 7, 1-7. [CrossRef]

26. Yang, X.; Lu, Y.; Liu, B.; Yao, J. Fiber Ring Laser Temperature Sensor Based on Liquid-Filled Photonic Crystal Fiber. IEEE Sens. J. 2017, 17, 6948-6952. [CrossRef]

27. Yang, J.; Guan, C.; Tian, P.; Chu, R.; Ye, P.; Wang, K.; Shi, J.; Yang, J.; Yuan, L. High sensitivity temperature sensor based on liquid filled hole-assisted dual-core fiber. Sens. Actuators A Phys. 2020, 303, 111696. [CrossRef]

28. Luo, M.; Liu, Y.G.; Wang, Z.; Han, T.; Wu, Z.; Guo, J.; Huang, W. Twin-resonance-coupling and high sensitivity sensing characteristics of a selectively fluid-filled microstructured optical fiber. Opt. Express 2013, 21, 30911-30917. [CrossRef]

29. Wang, Y.; Yang, M.; Wang, D.N.; Liao, C.R. Selectively Infiltrated Photonic Crystal Fiber with Ultrahigh Temperature Sensitivity. IEEE Photonics Technol. Lett. 2011, 23, 1520-1522. [CrossRef]

30. Li, Y.; Chen, Y.; Yi, D.; Du, Y.; Luo, W.; Hong, X.; Li, X.; Geng, Y.; Luo, D. A self-assembled fiber Mach-Zehnder interferometer based on liquid crystals. J. Mater. Chem. C 2020, 8, 11153-11159. [CrossRef] 